\title{
Increases in airway eosinophils and interleukin-5 with minimal bronchoconstriction during repeated low-dose allergen challenge in atopic asthmatics
}

\author{
I. Sulakvelidze, M.D Inman, T. Rerecich, P.M. O'Byrne
}

Increases in airway eosinophils and interleukin-5 with minimal bronchoconstriction during repeated low-dose allergen challenge in atopic asthmatics. I. Sulakvelidze, M.D. Inman, T. Rerecich, P.M. O'Byrne. CERS Journals Ltd 1998.

ABSTRACT: Repeated low-dose allergen challenge increases airway hyperresponsiveness in atopic asthmatics. However, it is not known whether low-dose allergen challenge increases airway inflammation.

Eight atopic asthmatics were enrolled in a controlled, cross-over study to evaluate the effect and time course of repeated low-dose allergen challenge on airway inflammation and hyperresponsiveness. The dose of allergen to reduce forced expiratory volume in one second (FEV1) by approximately $5 \%$ was selected in a screening allergen challenge. The subjects then were challenged for five consecutive days with either diluent or the selected low-dose of allergen. Methacholine airway hyperresponsiveness (PC20,meth) was measured and sputum induced on days 1,3 and 5 of the repeated challenge, and then 1 day and 3 days after the last challenge.

Repeated low-dose allergen challenge caused small reductions in FEV1, but increased airway eosinophils and interleukin (IL)-5, airway hyperresponsiveness, asthma symptoms and $\beta_{2}$-agonist use, all of which peaked on days 3 or 5 of the challenge. The mean (SEM) percentage sputum eosinophils was $21.2(0.7) \%$ after allergen versus $3.9(0.1) \%$ after diluent $(\mathrm{p}<0.001)$; percentage EG2+ cells were $13.4(0.3) \%$ after allergen versus $1.1(0.04) \%$ after diluent $(\mathbf{p}<0.01)$ and geometric mean (GSEM) eosinophil cationic protein (ECP) was $1061.8(1.6) \mu \mathrm{g} \cdot \mathrm{L}^{-1}$ after allergen versus 447.03 (1.2) $\mu \mathrm{g} \cdot \mathrm{L}^{-1}$ after diluent $(\mathbf{p}<0.05)$. Geometric mean (GSE) IL-5 was $71.4(1.4) \mathrm{pg} \cdot \mathrm{mL}^{-1}$ after allergen versus $18.4(1.04) \mathrm{pg} \cdot \mathrm{mL}^{-1}$ after diluent $(\mathrm{p}<0.01)$. All the changes had resolved by 3 days after the last challenges.

The study demonstrated that repeated inhalation of a low-dose of allergen causes airway eosinophilia and increases in interleukin-5, associated with airway hyperresponsiveness, and mild worsening of asthma control, without the development of marked acute bronchoconstriction or the development of late responses.

Eur Respir J 1998; 11: 821-827.

Asthma induced by the inhalation of various allergens in the clinical research laboratory, has been a model for studying pathophysiology and pathogenesis of this disease for many years [1-4]. The inhalation of a specific allergen by asthmatic subjects can cause three types of airway responses [5]: the isolated response, that develops within 1030 min after allergen challenge; the isolated late response that develops 3-8 $\mathrm{h}$ after the challenge; and the dual response, where subjects develop both early and late airway responses. The late response is associated with allergeninduced increases in airway responsiveness [6] and with eosinophilic airway inflammation [7].

The doses of allergen usually used to study experimentally induced asthma are of a magnitude that causes an early response of at least a $15 \%$ reduction in forced expiratory volume in one second $(\mathrm{FEV} 1)$ and a late response of at least $20 \%$ [5]. A shortcoming of this method is that these doses of allergen may be much higher than those to which patients with asthma are exposed in their natural

For editorial comments see page 798
Asthma Research Group, McMaster University, Hamilton, Ontario, Canada.

Correspondence: P.M. O'Byrne

Faculty of Health Sciences

Dept of Medicine

1200 Main St.

W. Hamilton

Ontario

Canada

Fax: 19055215053

Keywords: Airway responsiveness allergen

asthma

eosinophils

inflammation

Received: October 21997

Accepted after revision January 291998

Supported by the Medical Research Council of Canada. P.M. O'Byrne is a Medical Research Council of Canada Senior Scientist. environments. This shortcoming has been addressed by IHRE and co-workers [8, 9], who used airway challenge with a low-dose of allergen. At first, these investigators studied early and late responses after a single challenge with low-dose allergen [8]. Later, they used repeated lowdose allergen challenge and demonstrated a significant increase in airway hyperresponsiveness [9]. However, the role of airway inflammation in causing these changes, as well as the time course of these events, has not been studied previously.

The purposes of the present study were: 1) to determine the effects of repeated low-dose allergen challenge on airway inflammation as measured by numbers of eosinophils and metachromatic cells in induced sputum, as well as markers of eosinophil activation and level of the eosinopoietic cytokine IL-5; 2) to evaluate the effects of repeated low-dose allergen challenge on the development of late responses and methacholine airway hyperresponsiveness and to examine the time course of the changes; and 3) to evaluate the effects of repeated low-dose challenge on asthma symptoms and $\beta_{2}$-agonist use. 
Table 1. - Subject characteristics at the screening visit

\begin{tabular}{|c|c|c|c|c|c|c|}
\hline Sex & Age & $\begin{array}{l}\text { Allergen } \\
\text { type }\end{array}$ & $\begin{array}{l}\text { Screening allergen* } \\
\text { (dilution) }\end{array}$ & $\begin{array}{l}\text { Low-dose allergen+ } \\
\text { (dilution) }\end{array}$ & $\begin{array}{l}\text { FEV1 } \\
\% \text { pred }\end{array}$ & $\begin{array}{l}\mathrm{PC} 20 \text {,meth } \\
\mathrm{mg} \cdot \mathrm{mL}^{-1}\end{array}$ \\
\hline $\mathrm{M}$ & 26 & Cat & $1: 256$ & $1: 1024$ & 89.7 & 0.8 \\
\hline M & 22 & HDM & $1: 1024$ & $1: 8192$ & 81.2 & 1.9 \\
\hline M & 45 & HDM & $1: 8$ & $1: 64$ & 80.6 & 10.6 \\
\hline F & 23 & Ragweed & $1: 4$ & $1: 64$ & 112.1 & 8.0 \\
\hline M & 20 & Ragweed & $1: 256$ & $1: 1024$ & 93.1 & 3.5 \\
\hline M & 22 & Ragweed & $1: 16$ & $1: 256$ & 98.6 & 1.3 \\
\hline $\mathrm{F}$ & 19 & HDM & $1: 256$ & $1: 512$ & 93.2 & 1.1 \\
\hline M & 21 & HDM & $1: 4$ & $1: 64$ & 90.1 & 3.0 \\
\hline
\end{tabular}

*: top concentration of allergen used for allergen challenge producing an early asthmatic response of a $20 \%$ fall in FEV1; concentration of allergen used for repeated low-dose inhalations. FEV1: forced expiratory volume in one second; PC20,meth: provocative concentration of methacholine causing a 20\% fall in FEV1; M: male; F: female; HDM: house dust mite.

\section{Methods}

\section{Subjects}

Ten nonsmoking subjects with mild allergic asthma were recruited for the study (seven males, three females) (table 1). All subjects had had mild asthma symptoms for more than a year, that required only occasional use of $\beta_{2}$ agonists. They had no exacerbations of asthma or respiratory tract infections for at least 4 weeks before entering the study. Only subjects who had demonstrated a dual airway response during a screening allergen challenge were recruited. The subjects were asked to withhold $\beta_{2}$-agonists and caffeine containing beverages for 7-8 $\mathrm{h}$ before challenge tests. The study protocol was approved by the Ethics Committee of McMaster University Health Sciences Center and all subjects gave written informed consent to participate in the study. Only eight subjects completed the study. One subject was excluded because of inability to produce sputum, and one because of an exacerbation of asthma after the screening allergen challenge.

\section{Study design}

A cross-over study, comparing repeated allergen challenge with the allergen diluent was used to study the effects of repeated low-dose allergen challenge on airway inflammation and responsiveness. The primary outcome of the study was a change in sputum eosinophils. The secondary outcomes were numbers of sputum activated eosinophils (EG2+ cells), levels of eosinophil cationic protein (ECP) and IL-5, as well as metachromatic cells, blood eosinophils, methacholine airway responsiveness, FEV1, asthma symptoms and the use of $\beta_{2}$-agonists. The study was not randomized. In all subjects, diluent challenge was administered first, followed by the allergen challenge. Sub-jects were not randomly assigned to the allergen or diluent challenge because of uncertainty about the duration of the washout period needed to eliminate the consequences of the repeated inhalations of allergen. However, physiological and all sputum measurements were made by an investigator who was blind to the identity of the subjects.

Subjects were initially challenged with the diluent on five sequential weekdays, in the morning between 08:00 and 10:00 h. FEV1 measurements were taken before and every $10 \mathrm{~min}$ after the challenge, for $30 \mathrm{~min}$. On three weekdays, every other day, the subjects made a second visit to the laboratory between 14:00 and 16:00 h. During the second visit, they were challenged with methacholine and sputum was induced. One day and 3 days after the last repeated challenges subjects again visited the laboratory for methacholine challenge and sputum induction. At each visit subjects were asked to answer a questionnaire dealing with their asthma symptoms and use of $\beta_{2}$-agonists during the previous day. After 1 week washout, the subjects were crossed over and the same protocol was repeated, this time with the low-dose allergen challenge.

When selecting the appropriate low-dose of allergen to be used in the repeated challenge, we had two major objectives. Firstly, the dose should be significantly lower than that used in a conventional allergen challenge. Secondly, it should be large enough to induce small, but measurable, change in FEV1 to ensure that the subject did, in fact, respond to the allergen. A dose of allergen causing a fall in FEV1 of approximately 5\% satisfied both requirements. This low-dose was estimated during the screening visit when subjects were given conventional allergen challenge (table 1).

\section{Methacholine challenge test}

Methacholine challenge tests were performed using the method of CосксRоғт et al. [10]. Subjects first inhaled normal saline followed by increasing doubling concen-trations of methacholine until FEV1 fell by $20 \%$ or more from the baseline. Concentrations of methacholine were log-transformed and the concentration causing a $20 \%$ fall in FEV1 (PC20,meth) was calculated using a formula given by JuNIPER et al. [11].

\section{Conventional allergen challenge test}

Allergen challenge tests were performed according to the method described by O'ByRne et al. [5]. Based on the size of the allergy skin test and PC20,meth, the concentration of allergen that would cause a fall in FEV1 of $20 \%$ in each individual subject was calculated [12]. The challenge was started with a dose that was two doubling concentrations lower than the calculated dose. FEV1 was measured before and $10 \mathrm{~min}$ and $20 \mathrm{~min}$ after the challenge. If FEV1 did not fall by $20 \%$ or more, increasing doubling concentrations of allergen were administered until FEV1 had fallen by $20 \%$ or more from the baseline. FEV1 was then monitored at 30, 40, 50, 60, 90 and $120 \mathrm{~min}$ and then every hour, until $7 \mathrm{~h}$ after the challenge. 


\section{Repeated low-dose allergen challenge}

A dose of allergen that caused a $5 \%$ fall in FEV1 was determined during the screening allergen challenge. This dose was administered as a single challenge on the early mornings of five consecutive weekdays. Normal saline inhalations were administered in the early mornings of the control week.

\section{Sputum induction and analysis}

Sputum was induced using the method described by PIN et al. [13], by inhalation of a hypertonic saline. Concentrations of 3,4 and 5\% were inhaled for 7 min or until FEV1 dropped by $20 \%$. Salbutamol $(200 \mu \mathrm{g})$ was given $10 \mathrm{~min}$ prior to sputum induction and FEV1 was measured before and after the procedure. If enough sputum was ob-tained with any concentration of hypertonic saline, the challenge was discontinued. Plugs were selected from the obtained sputum sample and treated with $0.1 \%$ dithioth-reitol (Sputolysin; Calbiochem-Behring, San Diego, CA, USA) and Dulbecco's phosphate buffered saline (Gibco Diagnostics, Tucson, AZ, USA). Cytospins were then prepared on glass slides for histo- and immunohistochemical staining [14]. For differential cell count, slides were stain-ed with Diff-Quik (American Scientific Products, McGaw Park, IL, USA) and 400 cells were counted under the light microscope. For methachromatic cell counts, slides were stained with Toluidine Blue and 5,000 cells were counted. Activated eosinophils were detected through immunohistochemical staining of aptex-coated slides using a monoclonal EG2 antibody (Kabi Pharmacia, Uppsala, Sweden) directed against cleaved intracellular ECP. Sputum IL-5 was measured using enzyme-linked immunosorbent assay (ELISA) (R\&D, Minneapolis, MN, USA) and ECP was measured using radioimmunoassay (RIA) (Kabi Pharmacia, Uppsala, Sweden).

\section{Asthma symptoms and $\beta_{2}$-agonist use}

On the morning of each study day, subjects were given a questionnaire to report their daytime and night-time symptoms as well as use of $\beta_{2}$-agonists during the previous day. A four point grading scale for symptoms was used: $0=a b-$ sence of symptoms; $1=$ mild symptoms; $2=$ =moderate; and $3=$ severe symptoms. Use of $\beta_{2}$-agonists was expressed as the number of puffs. Oral prednisone tablets were dispensed to all subjects before the start of the study and a detailed written asthma self-management protocol was discussed and given to the subjects in the event of an asthma exacerbation during the study.

\section{Statistical analysis}

The primary outcome of the study was sputum eosinophils. Sample size was estimated based on our previous study of airway inflammation after conventional allergen challenge. An increase of $15 \%$ in sputum eosinophilia, dur-ing repeated allergen challenge, with a significance level of $\mathrm{p}=0.05$ and power of $80 \%$ required a study population of nine subjects. Secondary outcomes of the study were sputum EG2+ eosinophils, ECP and IL-5, sputum metachromatic cells, blood eosinophils, PC20,meth, FEV1, as-thma symptoms and use of inhaled $\beta_{2}$-agonists. PC20,meth data were log-transformed for analysis and are reported as geometric means (GSEM). Sputum eosinophils and EG2+ eosinophils were expressed as percentages and square root transformed for statistical analysis [15]. Sputum metachromatic cells were expressed as absolute numbers per 5,000 total counted cells, and square root transformed for analysis. However, the values reported for eosinophils, EG2+ eosinophils and metachromatic cells throughout the text represent anti-square root transformed means (anti-square root transformed SEM). Sputum ECP and IL-5 were log-transformed for statistical analysis; however, these variables are reported (analogous to PC20,meth) as geome-tric means (GSEM). Two-factor repeated measures analysis of variance (ANOVA) was used to analyse normalized data. The two independent variables were challenge type (diluent or allergen) and time (challenge day). Dependent variables have been already described in detail. Significance was accepted at the level of $\mathrm{p}=0.05$ and multiple comparisons were performed by Student-Neuwman-Kuels procedure.

\section{Results}

The dilutions of allergen used in the repeated challenges were between two and 16 fold lower than those used in the initial screening allergen challenges, with a median value of eightfold less (table 1).
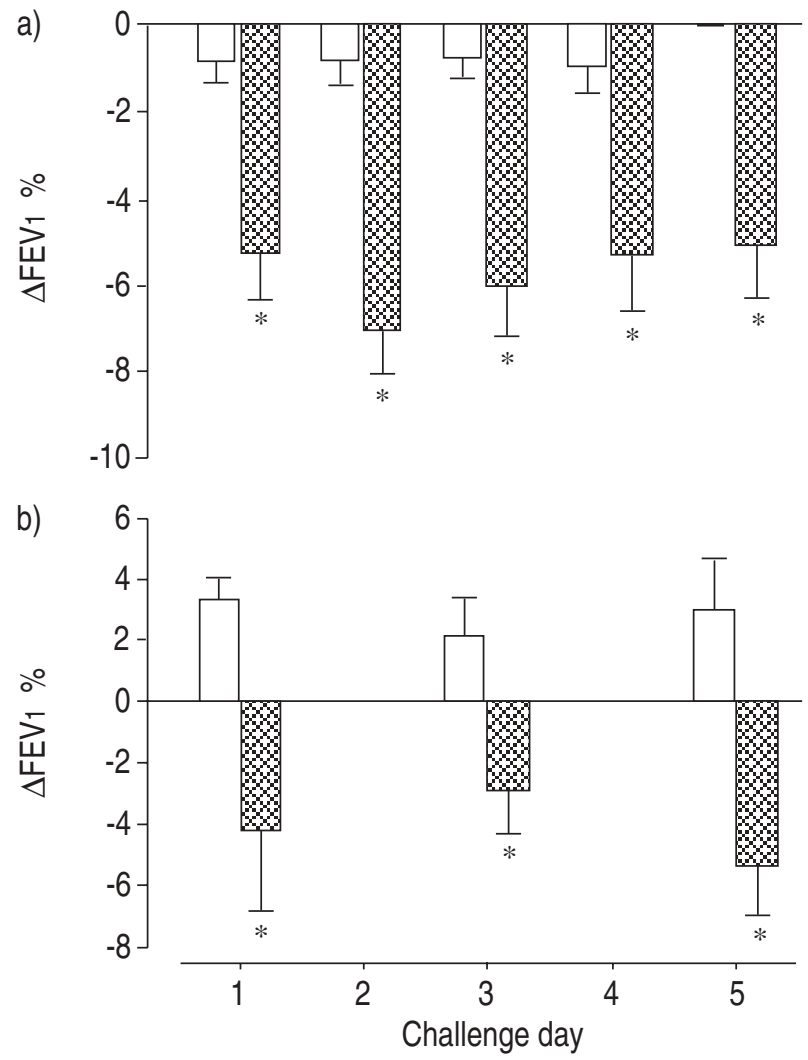

Fig. 1. - Mean ( \pm SEM) maximal early (0-30 min) (panel a) and late $(7 \mathrm{~h})$ (panel b) change in forced expiratory volume in one second $\left(\triangle \mathrm{FEV}_{1}\right)$ after repeated inhalation of diluent $(\square)$ or low-dose allergen ( $\varangle \times)$. The late responses were measured on days 1,3 and 5 of the repeated challenges. Repeated low-dose allergen challenge caused a small, but significant, fall in FEV 1 both early and late after challenge. *: $\mathrm{p}<0.05$. 
The mean ( \pm SEM) maximal immediate fall in FEV1 after low-dose allergen challenge was $7.01 \pm 1.02 \%$, compared to $0.9 \pm .0 .6 \%$ after diluent (fig. 1). The fall in FEV1 on each challenge day was significantly greater after low-dose allergen challenge compared to diluent $(\mathrm{p}<0.01)$. The mean ( \pm SEM) maximal fall in FEV1 measured $7 \mathrm{~h}$ after allergen challenge was $5.3 \pm 1.6 \%$ compared to an increase in FEV1 of $3.1 \pm 1.5 \%$ after diluent, which was achieved on day 5 (p<0.01) (fig. 1).

Repeated low-dose allergen challenge significantly increased night-time asthma symptoms $(\mathrm{p}<0.01)$, and nighttime $\beta_{2}$-agonist use $(p<0.01)$ (fig. 2). Significant increase in symptoms occurred on days 2, 3, 4 and 5. The increase in $\beta_{2}$-agonist use was only significant on day 5 . There was no significant difference in night-time symptoms and $\beta_{2^{-}}$

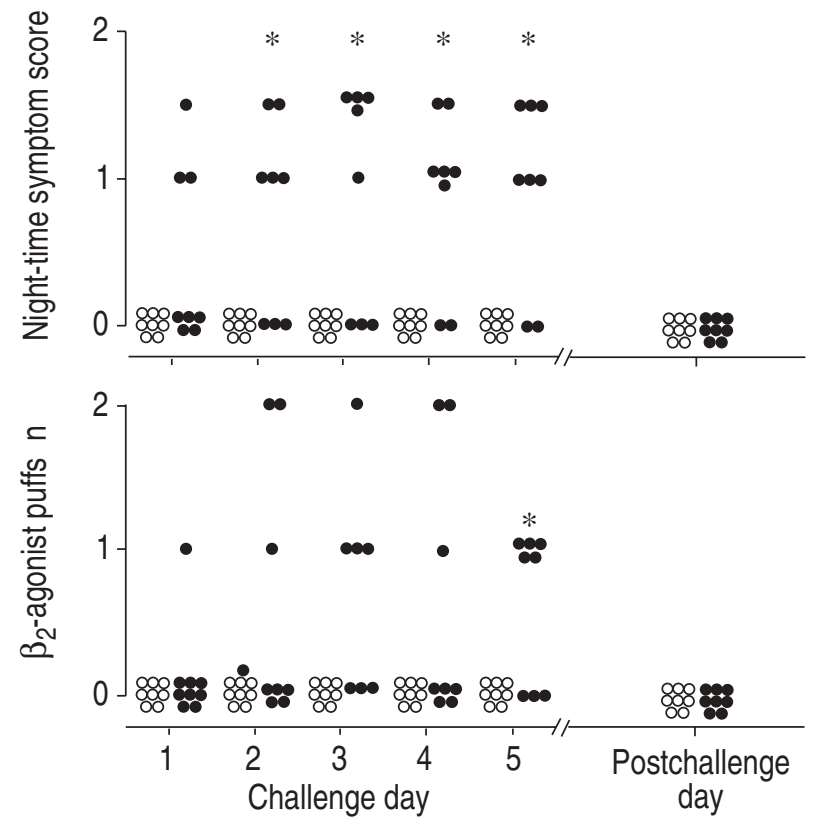

Fig. 2. - Nocturnal asthma symptoms and $\beta_{2}$-agonist use during repeated diluent $(O)$ or low-dose allergen $(\bullet)$ challenge. The repeated allergen challenges caused a significant increase in asthma symptoms and $\beta_{2}$-agonist use. These increases had resolved by 1 day after the repeated challenges. $*$ : $\mathrm{p}<0.05$.

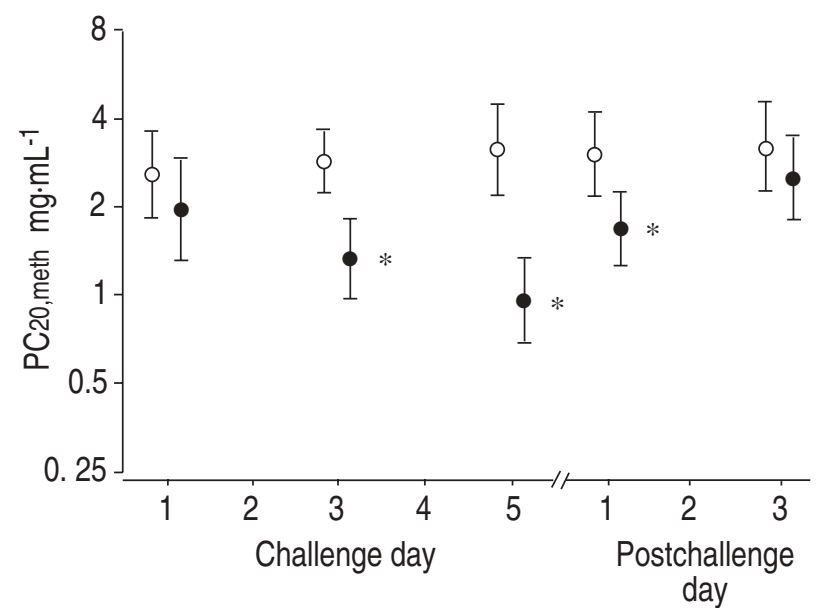

Fig. 3. - Provocative concentration of methacholine causing a $20 \%$ fall in forced expiratory volume in one second (PC20,meth) values (mean and GSEM) after repeated inhalation of diluent (O) or low-dose allergen $(\bullet)$. Repeated low-dose allergen challenge caused a significant reduction in PC20,meth, which had resolved by day 3 after the challenges. *: $\mathrm{p}<0.05$. agonist use between the allergen and placebo 1 day after the challenge.

Repeated low-dose allergen challenge significantly reduced PC20,meth (fig. 3). The effect was most marked on day 3, where the geometric mean PC20,meth was $1.3 \mathrm{mg}$. $\mathrm{mL}^{-1}$ (GSEM 1.4) after allergen compared to 2.8 (1.3) $\mathrm{mg}$. $\mathrm{mL}^{-1}$ after diluent $(\mathrm{p}<0.01)$ and day 5 , where the mean PC20,meth was $0.96(1.4) \mathrm{mg} \cdot \mathrm{mL}^{-1}$ after allergen compared to $3.2(1.4) \mathrm{mg} \cdot \mathrm{mL}^{-1}$ after diluent $(\mathrm{p}<0.01)$. A significant difference between the allergen and diluent periods was still present 1 day after the last challenges, when the mean PC20,meth was $1.7(1.3) \mathrm{mg} \cdot \mathrm{mL}^{-1}$ after allergen compared to $3.03(1.4) \mathrm{mg} \cdot \mathrm{mL}^{-1}$ after diluent $(\mathrm{p}<0.01)$. However, the effect had resolved by 3 days after the challenges, when the mean PC20,meth was $2.5(1.4) \mathrm{mg} \cdot \mathrm{mL}^{-1}$ after allergen compared to $3.2(1.4) \mathrm{mg} \cdot \mathrm{mL}^{-1}$ after diluent $(\mathrm{p}=0.5)$.

Repeated low-dose allergen challenge significantly increased sputum eosinophils, the increases being most marked on day 3, when the mean (SEM) value was $17.8(0.4) \%$ after allergen compared to $3.9(0.1) \%$ after diluent $(\mathrm{p}<$ 0.001 ), and day 5, where the mean value was $21.2(0.7) \%$ after allergen compared to $3.9(0.1) \%$ after diluent $(\mathrm{p}<$ 0.001 ) (fig. 4). However, no significant differences were present between the allergen and diluent periods 1 day after the last challenge.

EG2+ stained eosinophils also increased significantly during repeated low-dose allergen challenge, being most marked on day 3 where the mean value was $6.1(0.22) \%$ after allergen compared to $1.8(0.02) \%$ after diluent $(\mathrm{p}<$ $0.05)$ and day 5 , where the mean value was $13.4(0.3) \%$ after allergen compared to $1.1(0.04) \%$ after diluent $(\mathrm{p}<$ 0.01) (fig. 4). However, no significant differences were present in EG2+ cells between allergen and diluent periods 1 day after the last challenge.

Sputum ECP level was significantly higher during repeated low-dose allergen challenge than during diluent
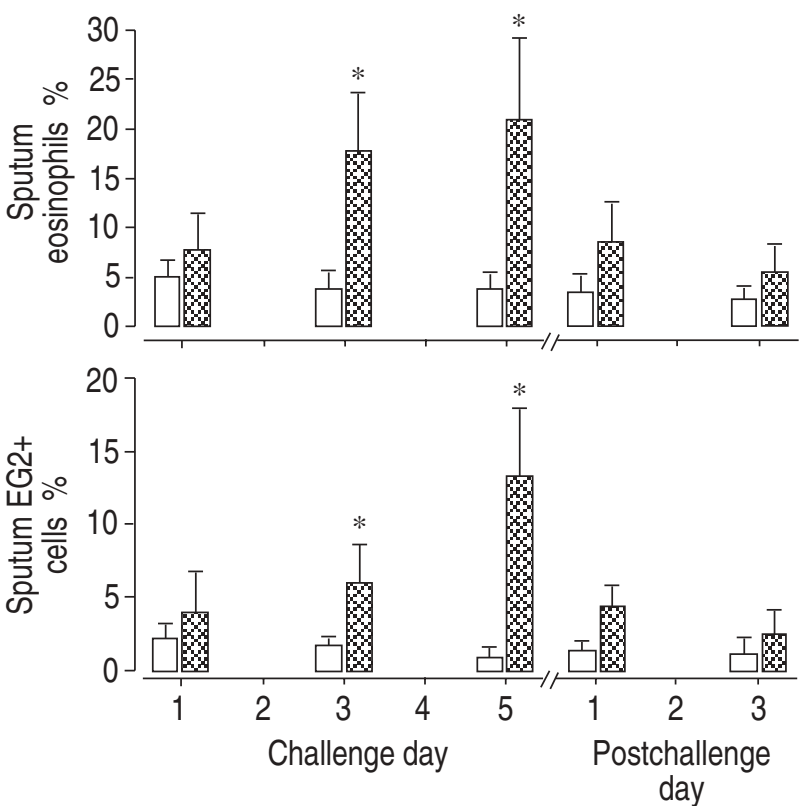

Fig. 4. - Changes in a) sputum eosinophils and b) EG2+ cells after repeated inhalation of diluent ( $\square$ ) or low-dose allergen ( $\$$ ) ) Repeated low-dose allergen challenge caused a significant increase in both eosinophils and EG2+ cells, which were maximal by day 5 of the challenges, and were no longer significantly increased by 1 day after the challenges. *: $\mathrm{p}<0.05$. 


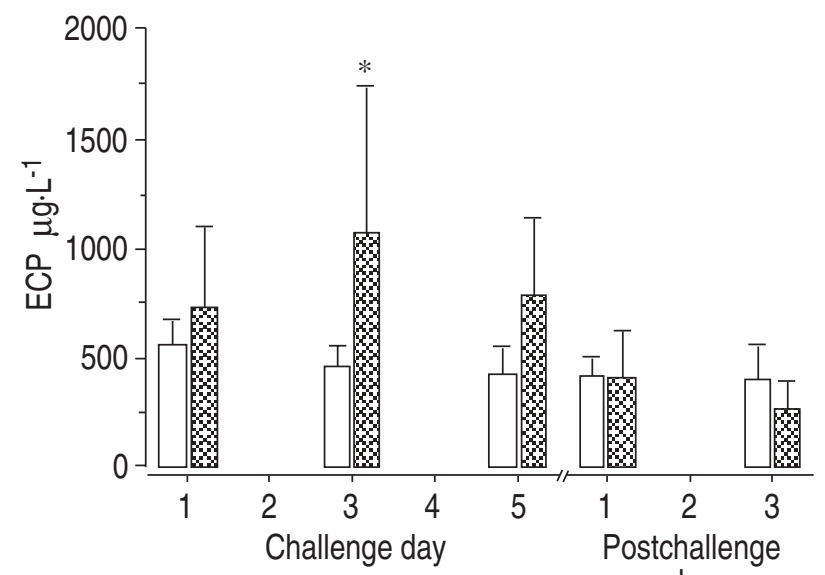

day

Fig. 5. - Changes in sputum eosinophil cationic protein (ECP) after repeated inhalation of diluent $(\square$ ) or low-dose allergen ( $\$$ ). Repeated low-dose allergen challenge caused a significant increase in sputum ECP, which was only significant on day 3 of the challenges. *: $\mathrm{p}<0.05$.

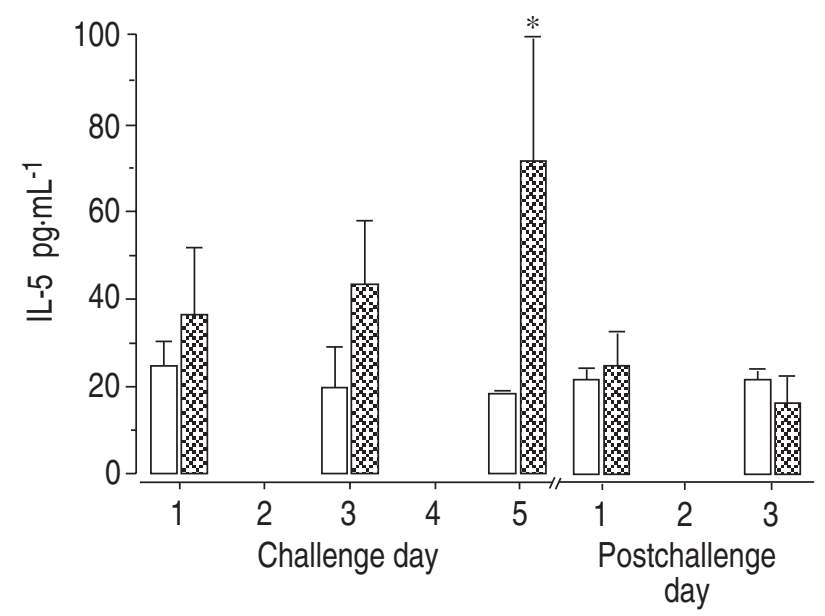

Fig. 6. - Changes in sputum interleukin (IL)-5 after repeated inhalation of diluent ( $\square$ ) or low-dose allergen ( $\times$ ). Repeated low-dose allergen challenge caused a significant increase in sputum IL-5, which was only significant on day 5 of the challenges. *: p<0.05.

challenge. The difference peaked on day 3 where the geometric mean value (GSEM) after allergen was 1061.8 (1.6) $\mu \mathrm{g} \cdot \mathrm{L}^{-1}$ compared to 447.03 (1.2) $\mu \mathrm{g} \cdot \mathrm{L}^{-1}$ after diluent $(\mathrm{p}<$ 0.05 ) (fig. 5). However, no significant difference was noted between the allergen and diluent periods 1 day after the last challenge.

During the diluent challenge period sputum IL-5 was either at the lowest measurable level or undetectable in the majority of subjects. However, during the low-dose allergen challenge period it became detectable in all subjects except one. The difference in IL-5 between the allergen and diluent challenges peaked on day 5 , the geometric mean value (GSEM) being $71.4(1.4) \mathrm{pg} \cdot \mathrm{mL}^{-1}$ after allergen compared to $18.4(1.04) \mathrm{pg} \cdot \mathrm{mL}^{-1}$ after diluent $(\mathrm{p}<0.01)$ (fig. $6)$. No differences were seen between allergen and diluent phases 1 day after the last challenges.

Sputum metachromatic cells increased significantly during repeated low dose allergen challenge. The greatest increases occurred on days 3 and 5, and metachromatic cells were still significantly increased 1 day, but not 3 days, after the last challenges. On day 3 the mean value (SEM) per

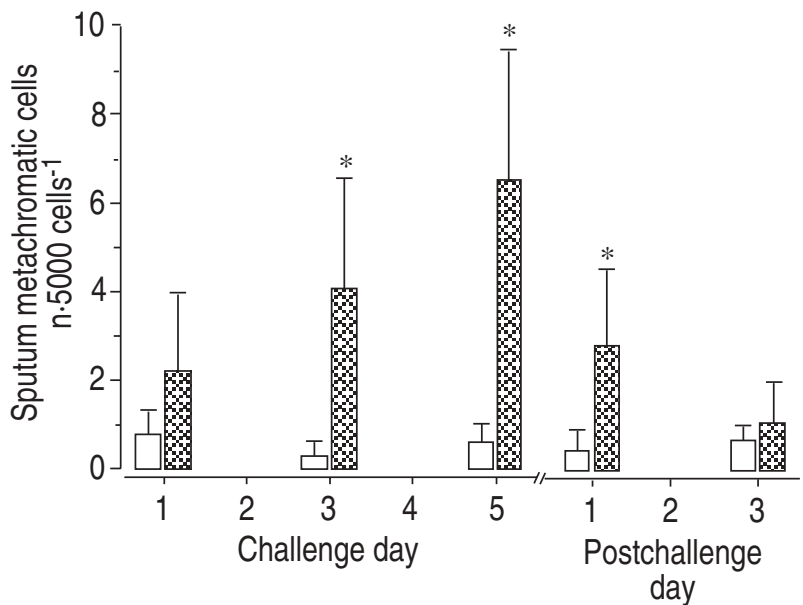

Fig. 7. - Changes in sputum metachromatic cells after repeated inhalation of diluent ( $\square$ ) or low-dose allergen ( $\$$ ). Repeated low-dose allergen challenge caused a significant increase in sputum metachromatic cells, which had resolved by day 3 after the challenges. *: $p<0.05$.

5,000 cells was $4.0(0.3)$ after allergen compared to 0.23 $(0.1)$ after diluent $(\mathrm{p}<0.01)$ and on day 5 , the mean value was $6.49(0.27)$ after allergen compared to $0.53(0.05)$ after diluent $(\mathrm{p}<0.001)$ (fig. 7). One day after allergen the mean value was $2.75(0.21)$ compared to 0.4 (0.07) after diluent $(\mathrm{p}<0.01)$.

Blood eosinophils overall were significantly increased only 1 day after the last of the repeated challenges, the mean value being $331.2 \pm 63.2$ after allergen compared to $218.7 \pm 46.2$ after diluent $(\mathrm{p}=0.04)$.

\section{Discussion}

This study has shown that repeated low-dose allergen challenge causes airway inflammation. This was demonstrated by significant increases in sputum eosinophils, EG2+ eosinophils and sputum supernatant ECP, as well as metachromatic cells on days 3 and 5 of allergen challenge compared to diluent challenge; however, these differences were no longer significant at 1 or 3 days after the last challenge. Sputum IL-5 also increased during the whole period of repeated allergen challenge compared to diluent; however, the peak level was reached on day 5. The study has also shown that repeated low-dose allergen challenge significantly increased airway responsiveness as early as day 3 of the challenge. This increase was still present at 1 day, but not 3 days, after the last challenge. Finally, repeated low-dose allergen challenge caused a slight, but significant, increase in nocturnal asthma symptoms and $\beta_{2}$-agonist use. These effects were obtained with concentrations of allergen that were a median eightfold lower than that used in conventional allergen challenges, and which were not associated with marked acute bronchoconstriction or the development of conventional late responses of a greater than $15 \%$ fall in FEV1.

The increase in sputum eosinophils and sputum EG2+ cells after repeated low-dose allergen challenge peaked on day 5 of the challenge and was associated with the largest changes in methacholine PC20,meth. The magnitude of the increase in sputum eosinophils is similar to that found by other investigators in sputum or bronchoalveolar lavage (BAL) after conventional allergen challenge [7, 16-18]. 
Interestingly, the changes in sputum eosinophils, EG2+ cells and methacholine airway hyperresponsiveness were accompanied by an increase in nocturnal asthma symptoms, as well as $\beta_{2}$-agonist use. These results are in agreement with other studies that have suggested the functional importance of activated eosinophils in asthma [19, 20].

Our finding of increased sputum ECP during repeated low-dose allergen challenge is in agreement with those studies that have shown increase in sputum ECP in stable asthma, as well as during exacerbations [21, 22]. In our study, sputum ECP peaked on day 3 of the repeated challenge, whereas the percentage of EG2-positive eosinophils peaked on day 5. These findings may mean that eosinophils contribute to the pathophysiological changes that occur in the later phase of the repeated low-dose allergen challenge through mechanisms other than secretion of ECP.

An important role has been ascribed to IL-5 in the pathogenesis of asthma by several investigators [23-25]. The present study has demonstrated an increase in IL-5 that was observed on the first day of allergen challenge, but only reached statistical significance on day 5 . These results are consistent with an important role for IL-5 in providing an appropriate environment for the maturation and prolonged survival of eosinophils newly recruited into the airways during repeated low-dose allergen challenge, and support an important role for IL-5 in this regard. The study has not identified the predominant source of IL-5, but parallel patterns of increase of IL-5 and eosinophils imply the possibility of a bidirectional interaction between them [25-27].

Sputum metachromatic cells, in common with eosinophils, significantly increased on day 3 and peaked on day 5 of repeated low-dose allergen challenge. However, unlike eosinophils, sputum metachromatic cells remained significantly increased on day 1 after the last challenge. The pattern of change in sputum metachromatic cells closely followed that of methacholine $\mathrm{PC} 20$,meth. There is evidence in the literature implicating metachromatic cells in the pathogenesis of asthma. PIN et al. [17] and Pizzichin et al. [28] demonstrated an increase in sputum metachromatic cells after allergen challenge or during the nat-ural course of disease. Furthermore, metachromatic cells obtained by bronchial brushings have been shown to correlate significantly with $\mathrm{PC} 20$,meth in asthma [29] and the mast cell-derived mediators histamine and tryptase have been increased in BAL in patients with symptomatic asthma [30].

There are other pathways, in addition to IL-5, that may have lead to the marked eosinophilia following repeated low-dose allergen challenge. One of these may be leukotriene dependent. Leukotrienes do have the capacity to attract eosinophils to the airways [31], in addition to playing an important role in allergen-induced early and late asthmatic responses [32]. Repeated low-dose allergen challenge may be an appropriate clinical model for sorting out the relative contribution of IL-5 and leukotrienes to asthmatic airway inflammation.

This study revealed rather fast resolution of the airway inflammation caused by repeated low-dose allergen challenge; all inflammatory indices returned to the baseline by 3 days after the last challenge. This suggests that endogenous anti-inflammatory mechanism(s) may be involved in resolving the inflammation, in an effort to minimize the tissue-damaging effects of repeated allergen challenge.
However, the precise mechanism of this resolution was not evaluated in this study.

The pattern of allergen inhalation during the study was designed to mimic the natural course of allergic asthma more closely than the conventional allergen inhalation challenge. Similar increases in airway hyperresponsiveness and airway inflammation have been described by several other groups who have studied these indices during natural pollen exposure $[7,33]$. The experimental approach of using conventional allergen challenge to study pathophysiology of asthma has been criticized [34]. The main reason for this criticism is the fact that allergen challenge involved brief single exposure to a high dose of allergen, which would not often occur in the everyday life of the majority of asthmatics. The use of repeated low-dose challenge does not fully get around this criticism, as the allergen is inhaled only once throughout the day, while natural allergen exposure is likely to be of even lower dose, and more prolonged. This study does demonstrate, however, that repeated doses of inhaled allergens, which cause very mild degrees of bronchoconstriction, can cause airway inflammation, airway hyperresponsiveness and slight deterioration of asthma control. We had initially postulated that, should this occur, the inhalation of the allergen on days 4 and 5 may be associated with more marked acute bronchoconstriction immediately after the challenge, or the development of late responses. However, the only progressive physiological abnormality that we could measure was the increase in airway hyperresponsiveness. This suggests that changes of methacholine airway hyperresponsiveness may be more sensitive to changes in the inflammatory status of the airways than late responses.

The potential advantages of repeated low-dose allergen challenge over conventional allergen challenge are not only the greater clinical relevance of the methods of challenge, but also the safety of the challenge, where no major bronchoconstrictor response is induced.

However, the repeated challenge is a major commitment for the subjects involved in the study, where 10 laboratory visits, of approximately $1 \mathrm{~h}$ each, are required for each of the allergen and diluent in each part of the study. This compares to three laboratory visits for each part of a conventional allergen challenge; however, if a late response is being evaluated, the time commitment is also approximately $10 \mathrm{~h}$. Also, in some laboratories, subjects are kept in hospital on the night of allergen challenge, because of concerns about development of severe late responses. This is unnecessary when a repeated low-dose challenge is performed.

The repeated challenge has provided somewhat different information with regards to allergen-induced airway inflammation, when compared to the conventional challenge. For example, there were no significant differences in any of the studied indices between allergen and placebo, at $7 \mathrm{~h}$ after the first of the repeated low-dose challenges. By contrast, the conventional challenge is accompanied by increased numbers of sputum eosinophils and metachromatic cells, and by airway hyperresponsiveness $7 \mathrm{~h}$ after the challenge $[6,35]$. Furthermore, we could not find significant differences in any of the physiological or inflammatory indices at 3 days after the last repeated allergen challenge. However, the changes caused by conventional allergen challenge last longer than 3 days [6]. 
In conclusion, this study has shown that repeated lowdose allergen challenge causes an increase in sputum eosinophils, activated eosinophils, eosinophil cationic protein and interleukin-5, as well as metachromatic cells. All of these inflammatory changes resolve by 3 days after the last allergen challenge. Also, repeated low-dose allergen challenge increases methacholine airway responsiveness, which persists for 1 day, but has resolved by 3 days after the last challenge. The repeated challenge is accompanied by a small but significant reduction in forced expiratory volume in one second, as well as an increase in asthma symptoms and use of $\beta_{2}$-agonists.

\section{References}

1. Booij-Noord H, De Vries K, Sluiter HJ, Orie NGM. Late bronchial obstructive reaction to experimental inhalation of house dust extract. Clin Allergy 1972; 2: 43-61.

2. Pepys J. Immunopathology of allergic lung disease. Clin Allergy 1973; 3: 1-22.

3. Cockcroft DW, Ruffin RE, Frith PA, et al. Determinants of allergen-induced asthma: dose of allergen, circulating IgE antibody concentration, and bronchial responsiveness to inhaled histamine. Am Rev Respir Med 1979; 120: 1053-1058.

4. Manning PJ, Rokach J, Malo JL, et al. Urinary leukotriene E4 levels during early and late asthmatic responses. J Allergy Clin Immunol 1990; 86: 211-220.

5. O'Byrne PM, Dolovich J, Hargreave FE. Late asthmatic responses. Am Rev Respir Dis 1987; 136: 740-751.

6. Cockroft DW, Ruffin RE, Dolovich J, Hargreave FE. Allergen-induced increase in non-allergen bronchial reactivity. Clin Allergy 1977; 7: 503-513.

7. Boulet LP, Cartier A, Thompson NC, Roberts RS, Dolovich J, Hargreave FE. Asthma and increases in nonallergic bronchial responsiveness from seasonal pollen exposure. J Allergy Clin Immunol 1983; 71: 399-406.

8. Ihre E, Axelsson IGK, Zetterstrom O. Late asthmatic reactions and bronchial variability after challenge with low doses of allergen. Clin Allergy 1988; 18: 557-567.

9. Ihre E, Zetterstrom O. Increase in non-specific bronchial responsiveness after repeated inhalation of low doses of allergen. Clin Exp Allergy 1993; 23: 557-567.

10. Cockcroft DW, Killian DN, Mellon JJA, Hargreave FE. Bronchial reactivity to inhaled histamine: a method and clinical survey. Clin Allergy 1977; 7: 235-243.

11. Juniper EF, Frith PA, Dunnett D, Cockcroft DW, Hargreave FE. Reproducibility and comparison of responses to inhaled histamine and methacholine. Thorax 1978; 33: 705-710.

12. Cockcroft DW, Murdock KY, Kirby J, Hargreave FE. Prediction of airway responsiveness to allergen from skin sensitivity to allergen and airway responsiveness to histamine. Am Rev Respir Dis 1987; 135: 264-267.

13. Pin I, Gibson PG, Kalendowicz R, et al. Use of induced sputum cell counts to investigate airway inflammation in asthma. Thorax 1992; 47: 25-29.

14. Popov T, Gottschalk R, Kolendowicz R, et al. The evaluation of a cell dispersion method of sputum examination. Clin Exp Allergy 1994; 24: 778-783.

15. Pizzichini MMM, Kidney JC, Wong BJO, et al. Effect of salmeterol compared with beclomethasone on allergeninduced asthmatic and inflammatory responses. Eur Respir J 1996; 9: 449-455.

16. De Monchy JGR, Kaufman HF, Venge P, et al. Bronchoalveolar eosinophilia during allergen-induced late asthmatic reactions. Am Rev Respir Dis 1985; 131: 373-376.

17. Pin I, Freitag AP, O'Byrne PM, et al. Changes in the cellular profile of induced sputum after allergen-induced asthmatic responses. Am Rev Respir Dis 1992; 145: 1265
1269.

18. Gauvreau GM, Doctor J, Watson RM, Jordana M, O'Byrne PM. Effects of inhaled budesonide on allergen-induced airway responses and airway inflammation. Am J Respir Crit Care Med 1996; 154: 1267-1271.

19. Griffin E, Hakansson L, Formgren H, Jorgensen K, Peterson $\mathrm{C}$, Venge $\mathrm{P}$. Blood eosinophil number and activity in relation to lung function in patients with asthma and with eosinophilia. J Allergy Clin Immunol 1991; 87: 548-557.

20. Skedinger M, Hallden G, Lundahl J, Hed J, Zetterstrom O. Eosinophil activity reflects clinical status in patients with asthma before and during a prednisolone course. Ann Allergy Asthma Immunol 1995; 74: 250-255.

21. Fahy JV, Liu J, Wong H, Boushey HA. Cellular and biochemical analysis of induced sputum from asthmatic and healthy subjects. Am Rev Respir Dis 1993; 147: 1126-1131.

22. Pizzichini MMM, Pizzichini E, Cleland L, et al. Sputum in severe exacerbations of asthma. Am J Respir Crit Care Med 1997; 155: 1501-1508.

23. Keatings VM, O'Connor BJ, Wright LG, Huston DP, Corrigan CJ, Barnes PJ. Late response to allergen is associated with increased concentrations of tumor necrosis factor-and IL-5 in induced sputum. J Allergy Clin Immunol 1997; 99: 693-698.

24. Jarjour NN, Calhoun WJ, Becky Kelly EA, Gleich GJ, Schwartz LB, Busse WW. The immediate and late allergic response to segmental bronchopulmonary provocation in asthma. Am J Respir Crit Care Med 1997; 155: $1515-1521$.

25. Okhawara Y, Lei X-F, Stampfli MR, Marshall JS, Xing Z, Jordana M. Cytokine and eosinophil responses in the lung, peripheral blood, and bone marrow compartments in a murine model allergen-induced airways inflammation. Am J Respir Cell Mol Biol 1997; 16: 510-520.

26. Broide DH, Paine MM, Firestein GS. Eosinophils express interleukin 5 and granulocyte macrophage-colony-stimulating factor mRNA at sites of allergic inflammation in asthmatics. J Clin Invest 1992; 90: 1414-1424.

27. Dubucquoi S, Desreumaux P, Janin A, et al. Interleukin synthesis by eosinophils: association with granules and immunoglobulin-dependent secretion. J Exp Med 1994; 179: 703-708.

28. Pizzichinni EM, Pizzichini MM, Efthimiadis A, et al. Indices of airway inflammation in induced sputum: reproducibility and validity of cell and fluid-phase measurements. Am J Respir Crit Care Med 1996; 154: 308-317.

29. Gibson PG, Allen CJ, Yang JP, et al. Intraepithelial mast cells in allergic and nonallergic asthma. Am Rev Respir Dis 1993; 148: 80-86.

30. Broide DH, Gleich GJ, Cuomo AJ, et al. Evidence of ongoing mast cell and eosinophil degranulation in symptomatic asthma airway. J Allergy Clin Immunol 1991; 88: 637-648.

31. Laitinen LA, Laitinen A, Haahtela T, Vikka V, Spur BW, Lee TH. Leukotriene E4 and granulocytic infiltration into asthmatic airways. Lancet 1993; 341: 989-990.

32. Hamilton AL, Watson RM, Wyile G, O'Byrne PM. A 5lipoxygenase activating protein antagonist, Bay 1005, attenuates both early and late phase allergen-induced bronchoconstriction in asthmatic subjects. Thorax 1997; 52: 348-354.

33. Altounyan REC. Changes in histamine and atropine responsiveness as a guide to diagnosis and evaluation of therapy in obstructive airways disease. In: Pepys J, Frankland AW, eds. Disodium Cromoglycate in Allergic Airways Disease. Edinburgh and London, Butterworths, 1970; pp. 47.

34. Wilson AF, Novey HS, Berke RA, Suprenant EL. Deposition of inhaled pollen and pollen extract in human airways. N Engl J Med 1977; 288: 1056-1060.

35. O'Byrne PM, Hargreave FE. Impact of monitoring inflammation on the management of adult asthmatic patient. Allergy 1993; 48: 153-157. 